\title{
Produção e disseminação de conhecimento: as temáticas abordadas em 19 anos da Revista Brasileira de Estudos Urbanos e Regionais (RBEUR)
}

\author{
Production and dissemination of knowledge: the thematics addressed in 19 years of The \\ Brazilian Journal of Urban and Regional Studies (RBEUR)
}

\author{
Rubens Staloch \\ Doutorando em Planejamento Territorial e Desenvolvimento Socioambiental \\ Universidade do Estado de Santa Catarina \\ rubens.staloch@udesc.br \\ Isa de Oliveira Rocha \\ Doutora em Geografia Humana \\ Universidade do Estado de Santa Catarina \\ isa.rocha@udesc.br
}

\begin{abstract}
Resumo
A expansão dos Programas da área de Planejamento Urbano e Regional e Demografia (PLURD) ocorreu após a década de 1990, mais precisamente, nos anos 2000, inclusive, com a criação dos Mestrados Profissionais. Junto deste processo de expansão "nascia", em 1999, a Revista Brasileira de Estudos Urbanos e Regionais (RBEUR), parte importante da Associação Nacional de Pós-Graduação e Pesquisa em Planejamento Urbano e Regional (ANPUR). Trata-se de uma "vitrine" de temáticas recorrentes e pertinentes à área. Assim, o presente artigo visa analisar de forma quantitativa e descritiva as temáticas abordadas nos artigos publicados na RBEUR. A metodologia de análise é entendida como descritiva, por meio de análise de conteúdo, bem como, quantitativa pelo processamento dos dados efetuado. Considerando o período de 1999 (sua primeira edição) a 2018 (v. 20, n. 2), se constatou que a temática "planejamento e gestão urbana e/ou regional" (dentre 24 elencadas) é aquela que mais se destaca entre o total de 322 artigos publicados nos 19 anos de existência da Revista. Igualmente, verificou-se que a concentração geográfica dos Programas de Pós-Graduação em PLURD coincide com as instituições de origem da grande parte dos autores das publicações da RBEUR: Sudeste, Sul e Nordeste.
\end{abstract}

\section{Palavras-chave}

Planejamento urbano e regional. Demografia. Revista Brasileira de Estudos Urbanos e Regionais (RBEUR). Bibliometria. Temáticas. Artigos.

\section{Abstract}

The expansion of the Programs of Urban and Regional Planning and Demography took place after the 1990s, more precisely, in the years 2000, with the creation of the Professional Master's Degrees. Along with this expansion process, the Brazilian Journal of Urban and Regional Studies (RBEUR), an important part of the National Association of Postgraduate and Research in Urban and Regional Planning (ANPUR), was born in 1999. It is a "showcase" of recurring themes pertinent to the area. In this way, the present article aims to analyze in a quantitative and descriptive way the topics addressed in the articles published in the RBEUR. The methodology of analysis is understood as descriptive, by means of content analysis, as well as, quantitative by the processing of the data made. Con- 
sidering the period from 1999 (its first edition) to 2018 (v. 20, n. 2), it was found that the theme "urban and / or regional planning and management" [among the 24 listed] is the one that stands out among the total of 322 articles published in the 19 years of existence of the Journal. Likewise, it was verified that the geographical concentration of the Postgraduate Programs in PLURD coincides with the institutions of origin of the great part of the authors of the RBEUR publications: Southeast; South and Northeast.

\section{Keywords}

Urban and Regional Planning. Demography. Brazilian Journal of Urban and Regional Studies (RBEUR). Bibliometry. Thematic. Articles.

\section{INTRODUÇÃO}

Considerando o cenário das Pós-Graduações no Brasil, de acordo com a Coordenação de Aperfeiçoamento de Pessoal de Nível Superior (CAPES), a Grande Área do Conhecimento denominada de Ciências Sociais Aplicadas é composta por outras sete subáreas ${ }^{1}$, dentre elas, Planejamento Urbano e Regional e Demografia (PLURD). Apesar do significativo aumento do número de Programas da Área PLURD, em 47 anos - 1970 a 2017 - o número passou de 6 para 46 Programas ${ }^{2}$, ainda estão concentrados, sobremaneira, nas regiões Sudeste e Sul do país.

No âmbito do escopo da Associação Nacional de Pós-graduação e Pesquisa em Planejamento Urbano e Regional (ANPUR), fica evidente que a Revista Brasileira de Estudos Urbanos e Regionais (RBEUR) é reconhecida como o principal periódico da área Planejamento Urbano e Regional (FERNANDES, 2016). Nesta perspectiva, o presente trabalho tem como foco perfazer uma análise quantitativa e descritiva no que diz respeito às temáticas abordadas nos artigos publicados na Revista Brasileira de Estudos Urbanos e Regionais (RBEUR), desde sua primeira edição, em 1999, até a mais recente, em 2018.

Cabe mencionar que o trabalho foi motivado pelo fato de poder apresentar a pesquisadores e interessados na área a abrangência das publicações RBEUR, não apenas como fonte para busca de materiais bibliográficos, mas, sobretudo, pelas temáticas atualizadas e preocupadas com a disseminação do conhecimento, acima de tudo, com olhar crítico, mostrando inclusive, vieses de caminhos à área PLURD, e por que não dizer, ao planejamento e desenvolvimento urbano e regional do país.

Posto isto, o texto está dividido em cinco seções para além destas notas introdutórias: A Pós-Graduação na área de Planejamento Urbano e Regional e Demografia no Brasil: breves notas; A Revista Brasileira de Estudos Urbanos e Regionais; Metodologia de coleta e análise dos dados; Dados e análise: de onde e quais são as temáticas das publicações da RBEUR (1999-2018)?; e Notas finais: para onde se caminha?

\footnotetext{
${ }^{1}$ Fazem parte da Grande Área das Ciências Sociais Aplicada das CAPES as subáreas de avaliação: 1) Direito [Direito]; 2) Administração, Ciências Contábeis e Turismo [Administração, Turismo]; 3) Economia [Economia]; 4) Arquitetura e Urbanismo [Arquitetura e Urbanismo]; 5) Planejamento Urbano e Regional e Demografia [Planejamento Urbano e Regional, Demografia]; 6) Ciências Sociais Aplicadas I [Ciência da Informação, Museologia, Comunicação]; 7) Serviço Social [Serviço Social];

${ }^{2}$ Atualmente, dados de julho/2018, são 46 Programas em andamento, segundo Plataforma Sucupira - CAPES.
} 


\section{PÓS-GRADUAÇÃo NA ÁREA DE PLANEJAMENTO URBANO E REGIONAL E DEMOGRAFIA NO BRASIL: BREVES NOTAS}

Tendo em vista o estímulo do governo brasileiro, durante as décadas de 1960 e 1970, a Pós-Graduação no Brasil toma forma, contribuindo "[...] para a expansão do próprio sistema e para a promoção da pesquisa científica e tecnológica no País." (PIQUET; VILANI, 2013, p. 96). De acordo com dados do Centro de Gestão e Estudos Estratégicos (CGEE) (2012, p. 39), no ano de 1965, quando foi regulamentada a Pós-Graduação no país, havia apenas 27 Programas de Mestrado. Em 1975, já eram 429 e em 1996, 1.187. Os Programas de Doutorado somavam 11 em 1965, 149 em 1975 e em 1998, totalizavam 782. Atualmente (considerando dados da Plataforma Sucupira acessada em jul./2018), existem 4.341 Programas de Pós-Graduação (entre Mestrados Acadêmicos (ME), Doutorados (DO) e Mestrados Profissionais $(\mathrm{MP}))^{3}$. Os 46 Programas da área PLURD representam $1 \%$ do total de Programas avaliados e qualificados pela CAPES e 7\% do total de Programas da Grande Área das Ciências Sociais Aplicadas.

No âmbito das regiões brasileiras, as Pós-Graduações se apresentam em destaque, de acordo com maior número ofertado, nas regiões Sudeste, Sul e Nordeste, respectivamente, em ordem decrescente. Assim como se percebe ao longo dos tempos, porém, não de forma constante e homogênea, o aumento do número de Programas de Pós-Graduação e Cursos, também se verifica um número crescente de alunos matriculados, acima de tudo, em nível de ME e DO (CAPES, 2017).

A área de avaliação em Planejamento Urbano e Regional e Demografia (PLURD) está composta por duas subáreas: 1) Planejamento Urbano e Regional (PUR) e 2) Demografia (D). Atualmente, estão ativos 42 Programas na subárea PUR e 4 em Demografia. A primeira subárea originou-se da criação, no início da década de 1970, dos primeiros cursos de mestrado com a finalidade de formar quadros qualificados, tanto para a formulação como para a implementação de políticas urbanas e regionais (estipuladas e idealizadas pelo regime militar no período). (Quadro 1)

Quadro 1 - Primeiros cursos da área - gênese

\begin{tabular}{|c|c|c|c|}
\hline Região & Instituição & Grau / Subárea & Ano \\
\hline Sul & UFRGS & ME / PUR & 1970 \\
\hline Sudeste & UFRJ & ME / PUR & 1972 \\
\hline Nordeste & UFPE & ME / PUR & 1975 \\
\hline Sudeste & UFMG & ME / D & 1985 \\
\hline
\end{tabular}

Fonte: elaborado a partir dos dados coletados no Relatório de Avaliação 2017 da CAPES e da Plataforma Sucupira (acessado em julho de 2018).

A partir desta perspectiva, Porto e Theis (2016) descrevem o período de 1970 a 1999 como a "gênese" dos Programas de Planejamento Urbano e Regional. Limonad (2017) desta-

\footnotetext{
3 Importante destacar que em 1976 a CAPES normatizou o Sistema de Avaliação da Pós-Graduação no Brasil, que, por sua vez, está ativo até hoje para diferentes áreas de avaliação. Os critérios de avaliação versam sobre o estabelecimento de padrões de qualidade dos cursos, o estímulo ao impulso da evolução do Sistema Nacional de Pós-Graduação, bem como de cada Programa, em particular, e, ainda, visa contribuir com o aumento da eficiência dos Programas para atender às necessidades nacionais, regionais e urbanas (PORTO; THEIS, 2016). Os Programas de Pós-Graduação Stricto Sensu são avaliados anualmente pela CAPES, uma tarefa complexa e que envolve diversos critérios/quesitos: 1) Proposta do Programa; 2) Corpo Docente; 3) Corpo Discente; 4) Produção Intelectual; 5) Inserção Social.
} 
ca que estes programas de PUR se constituíram no âmbito do II Plano Nacional de Desenvolvimento (PND), a partir de um convênio realizado entre CAPES (Ministério da Educação) e o Ministério do Interior. Durante a década de 1980 não houve criação de Programas na área PUR, "[...] sendo sintomático que no período de quase 20 anos (entre 1975 e 1993) nenhum novo curso tenha sido proposto na área." (PIQUET; VILANI, 2013, p. 100, grifo dos autores). A partir dos anos de 1990, sobretudo, após os anos 2000, com as novas políticas econômicas, sociais etc. do país, os Programas na área PUR e D (denominados agora PLURD) "deslancharam", inclusive, no período mencionado se inicia a fase de criação dos Mestrados Profissionais (MP). (Gráfico 1)

Gráfico 1 - Desenvolvimento dos Cursos da área PLURD (1970-2017)

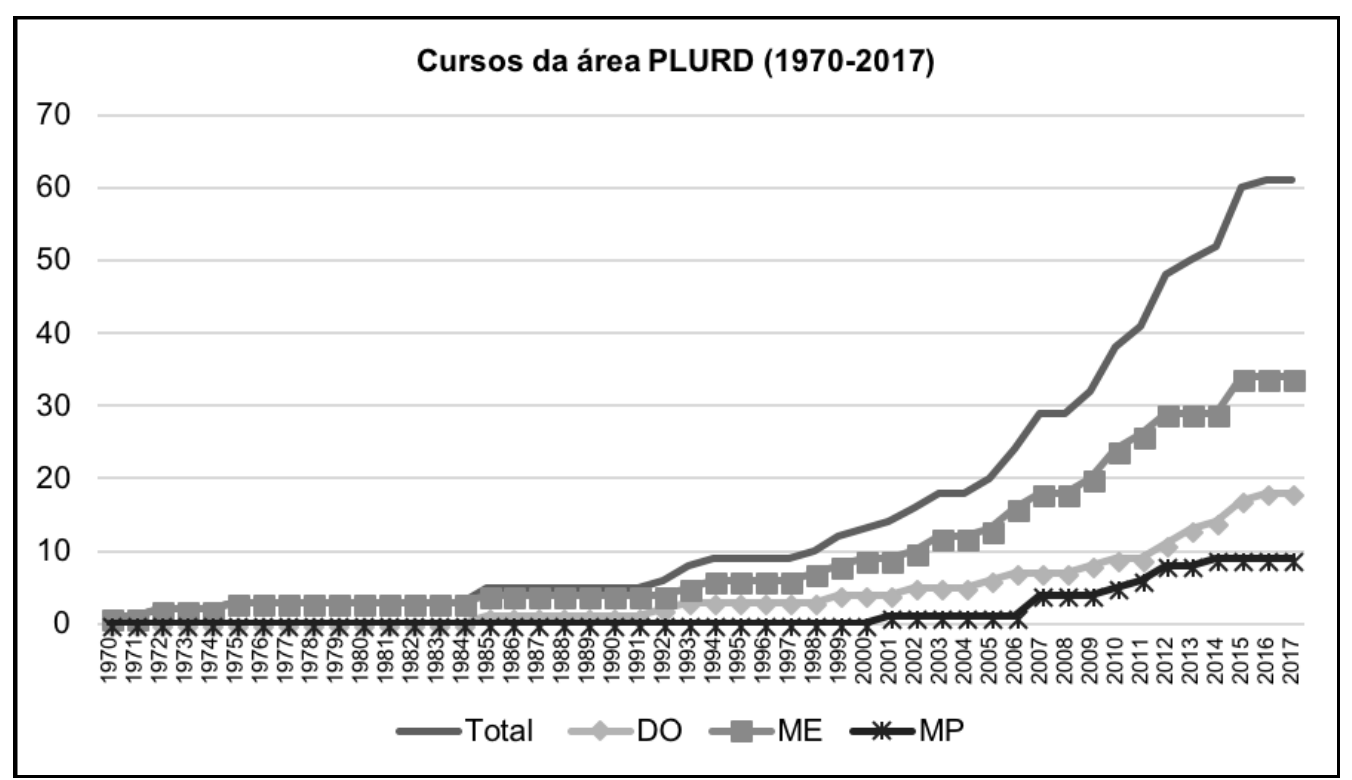

Fonte: elaborado a partir dos dados coletados no Relatório de Avaliação 2017 da CAPES e da Plataforma Sucupira (acessado em julho de 2018).

Quanto aos MP (em menor parcela, visualizado no Gráfico 1), o primeiro deles surgiu em 2001 na Universidade Cândido Mendes (UCAM), em Campos dos Goytacazes (RJ), na região Sudeste; sendo esta também precursora na área pela criação de um DO (acadêmico) a partir de um MP. E, assim, se pode dizer que as instituições de status jurídico privado foram as grandes responsáveis pelas instalações dos MP no país dos quais, ainda hoje, dos oito MP da área PLURD, cinco são ofertados por instituições de status jurídico privado. De um total de 62 cursos, distribuídos nos 46 Programas, apenas 1\% são "Profissionais".

Por ora, mesmo com a aprovação/autorização para criação de doutorados profissionais $^{4}$ no país, na área de avaliação PLURD até jul./2018 não havia proposta aprovada nesta modalidade. Ao analisar os dados sobre a evolução dos Programas, é inegável que há uma evolução na quantidade ofertada, porém, não de forma homogênea (geograficamente) e constante (temporalmente) $)^{5}$. O que mais evidente fica é a "lacuna" no território brasileiro (região Norte e Centro-Oeste, sobremaneira) na oferta de Programas na área de avaliação CAPES de PLURD. Ademais, a região Nordeste, também se encontra relativamente desassis-

\footnotetext{
${ }^{4}$ Instituído pela Portaria n 389, de 23 de março de 2017, do Ministério da Educação (MEC).

${ }^{5}$ A maior parte destes Programas estão avaliados com notas 3 e 4, destacando, a quantidade de apenas um Programa com nota 7, sendo este o Programa em Demografia da Universidade Federal de Minas Gerais (UFMG).
} 
tida por Programas na área, tendo em vista que em cinco Unidades Federativas não há a presença de mestrados e de doutorados.

De forma geral, se pode destacar que: a) a maior parte dos Programas está concentrada nas regiões Sul, Sudeste e Nordeste do país; b) o Sul é a única região em que todas as suas Unidades Federativas possuem cursos na área ${ }^{6}$; c) as regiões Nordeste e Norte são aquelas que possuem a maior quantidade de Unidades Federativas sem cursos na área analisada; d) em dez Unidades da Federação (Sudeste: Espírito Santo; Norte: Acre, Amazonas, Rondônia; Centro-Oeste: Distrito Federal, Mato Grosso; Nordeste: Alagoas, Ceará, Piauí, Sergipe) não existem cursos na área PLURD.

Este processo de expansão dos Programas na área PLURD expressa o resultado de apoio coletivo, sobretudo da ANPUR. Fundada em 1983, a Associação, desde então ampliou significativamente o número e o espectro de instituições associadas e filiadas. São organizados Encontros Nacionais a cada dois anos (ENANPUR), dos quais são regularmente publicados Anais. Em 1997 a ANPUR instituiu o Prêmio Brasileiro "Política e Planejamento Urbano e Regional", de frequência bienal, que contempla a produção nesse amplo campo de atividades nas categorias: livro, tese de doutorado e dissertação de mestrado. Em 1999 a ANPUR lançou a Revista Brasileira de Estudos Urbanos e Regionais (RBEUR), com periodicidade semestral e a partir de 2015 passou a ter periodicidade quadrimestral (ANPUR, 2018). O Relatório de Avaliação 2017 da CAPES ainda revelou um dado muito interessante: os docentes e discentes dos PLURD publicaram em 1.648 periódicos. A este respeito, de acordo com a Plataforma Sucupira (jul./2018), estão classificados na área PLURD 1.902 periódicos ${ }^{7}$, sendo que a maior parte deles está nos estratos "B5" e "B4". (Gráfico 2)

Gráfico 2 - Classificações dos periódicos avaliados para Área PLURD

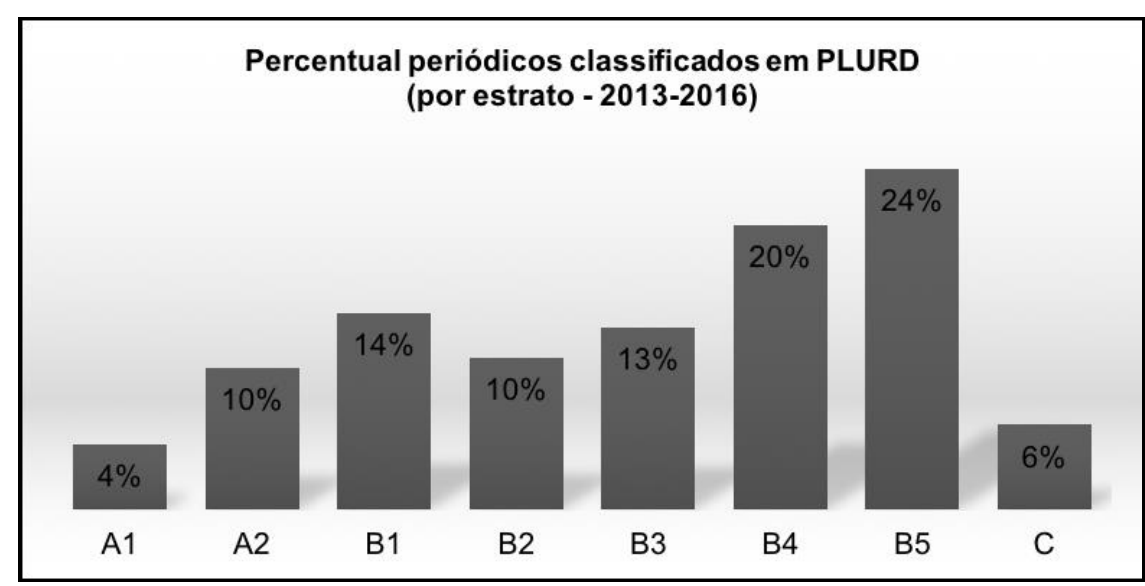

Fonte: elaborado com base nos dados da Plataforma Sucupira (jul./2018).

Neste rol está a RBEUR, como já destacado, braço importante da ANPUR. O periódico é o mais significativo meio de divulgação de estudos na área, sendo avaliado pela CAPES (quadriênio 2013-2016) com Qualis “A2"8. Expostas as questões gerais sobre o processo de desenvolvimento da área PLURD, e utilizando a correlação realizada acerca da produção in-

\footnotetext{
${ }^{6}$ Inclusive, um dos últimos Programas (Doutorado Acadêmico) foi aprovado pela Capes em Santa Catarina, no ano de 2016. É o Programa de Pós-Graduação em Planejamento Territorial e Desenvolvimento Socioambiental (PPGPLAN) da Universidade do Estado de Santa Catarina (UDESC).

7 A RBEUR é, no âmbito da ANPUR, como aponta Limonad (2017), um dos principais meios para dar a necessária e objetivada visibilidade à Associação.

${ }^{8}$ Apresenta Qualis para outras dez áreas de avaliação, conforme dados da plataforma Sucupira.
} 
telectual, concentramos a partir de agora nos esforços para responder a problemática central deste trabalho: de onde foram e quais as temáticas abordadas nos 19 anos de publicações da RBEUR?

\title{
3 A REVISTA BRASILEIRA DE ESTUDOS URBANOS E REGIONAIS: NOTAS DESDE SUA GÊNESE
}

A RBEUR iniciou sua trajetória de publicações e disseminação de conhecimento e diálogos crítico-reflexivos em 1999, quando o país apresentava, ao final do período, 11 Programas na área PLURD (todos acadêmicos). No editorial da primeira edição, intitulado "Aleluia!", fica evidente a vontade da criação e disseminação de uma Revista que contemplasse os debates da área de Planejamento Urbano e Regional. Nasceu assim, a RBEUR, em 1999, "praticamente junto com a ANPUR" (GONÇALVES, 1999, p. 3). A Revista adquiriu uma característica mais objetiva

[...] durante a gestão de Carlos Vainer: organizado pela diretora Cristina Leme, o 1응 Encontro de Editoria Científica em Estudos Urbanos e Regionais discutiu uma política de divulgação da produção científica nesse campo e propôs, entre outras conclusões, a criação de uma revista pela Anpur, que contemplasse o campo multidisciplinar desses estudos. (GONÇALVES, 1999, p. 3).

Desde 1999, então, veio se consolidando (atualmente consolidada, considerando sua classificação Qualis "A") como o principal periódico da área de Planejamento Urbano e Regional no Brasil ${ }^{9}$. A partir de 2015 sua periodicidade passou a ser quadrimestral ${ }^{10}$ (até então era semestral), com média (atual - jul./2018) de nove artigos por volume.

\begin{abstract}
Seu propósito é oferecer à comunidade acadêmica um espaço para disseminação do conhecimento no campo do planejamento e dos estudos urbanos e regionais, guardando a amplitude temática característica da ANPUR e pautando-se pelo estímulo à diversidade de pensamento e pela exigência de rigor e excelência nos textos publicados. Publica artigos inéditos, de perfil teórico-conceitual ou aplicado, com resultados de pesquisas, ou ainda de caráter metodológico e histórico [...] (FERNANDES, 2016, p. 1).
\end{abstract}

Como lembra Limonad (2017), no âmbito da ANPUR, quando Ana Clara Ribeiro assumiu sua presidência, em 2011, era seu objetivo, além de reforçar a perspectiva da instituição, estimular a área de pesquisa e ensino de planejamento urbano e regional, sendo um dos meios, a RBEUR e os seminários temáticos, como por exemplo: História da Cidade e do Urbanismo; de Ensino, Pesquisa e Extensão em Planejamento Urbano e Regional; e o de Áreas de Preservação Permanente Urbanas. Desta forma, se tinha como eixos de ação: a) fortalecimento institucional; b) relações institucionais; e c) produção acadêmica (LIMONAD, 2017). Sobre o terceiro eixo, conforme a autora, estava centrado na promoção do fortalecimento da RBEUR enquanto veículo institucional da associação e no aumento da interação com os membros da associação. Este fortalecimento contou com a sua inserção em uma base de dados digital, de fácil acesso.

\footnotetext{
${ }^{9}$ Está registrada com o ISSN eletrônico 2317-1529 e o ISSN impresso 1517-4115.

${ }^{10}$ São 14 indexadores, repositórios e bases de dados. A avaliação dos manuscritos é realizada por meio de processo de avaliação pelos pares, cujo resultado pode ser: a) publicação sem modificações; b) publicação com modificações não substanciais; c) ressubmissão a um novo processo de avaliação após modificações substanciais; e d) rejeição. Os artigos aprovados costumam ser publicados em até 1 ano após a sua submissão.
} 


\begin{abstract}
Optou-se nesse sentido, ainda durante o interstício de Ana Clara Torres Ribeiro, implantar a revista na base de software aberto Open Jornal System (OJS). Essa disponibilização foi alcançada em outubro de 2011 e disponibilizada em dezembro de 2011. Isso só se fez possível graças ao trabalho diligente de digitalização dos anais pelas gestões precedentes de Edna Castro (2007-2009) e Leila Christina Duarte Dias (2009-2011). A disponibilização da revista no formato OJS, com sistema indexado de busca por autores e palavras-chave, contribuiu para ampliar a difusão da revista e aumentar de forma significativa a visibilidade da ANPUR ao nível mundial. Alcançamos em julho de 2013 de 50 a 100 novos acessos por dia, das mais diversas partes do mundo, e que vai ao encontro das exigências da SciELO e da Red de Revistas Cientificas de America Latina y el Caribe, España y Portugal (Redalyc). (LIMONAD, 2017, p. 228).
\end{abstract}

Ainda, se pode citar como seu fortalecimento e, sobretudo, passos para a melhor qualificação em termos de estratos, sua disponibilidade no Portal de Periódicos CAPES, no Sistema de Editoração Eletrônica de Revistas (SEER) do Instituto Brasileiro de Informação em Ciência e Tecnologia (IBICT), e sua aprovação no CrossRef, o que garante a todas as publicações online da ANPUR um Digital Object Identifier (DOI). Como aponta Limonad (2017), é preciso reforçar a visibilidade da associação (ANPUR) por meio dos seus principais veículos, como os anais e a RBEUR, a qual, por sinal, tem contribuído, e muito, para o processo de reflexão e disseminação de importantes contribuições à área.

O conteúdo da RBEUR se dirige a um público multidisciplinar de professores, pesquisadores, estudantes e profissionais do campo do planejamento e dos estudos urbanos e regionais. De acordo com dados da Revista, atualmente (jul./2018), possui como editor responsável Jose Tavares Correia de Lira da Universidade de São Paulo (USP), Departamento de História da Arquitetura e Estética do Projeto (São Paulo/SP) e editora assistente Maria Cristina da Silva Leme, USP, Departamento de Projeto (São Paulo/SP). De acordo com dados apresentados no Relatório 2016 da Revista, Fernandes (2016) demonstra que há uma linha crescente do número de submissões, considerando o comparativo dos anos de 2014, 2015 e 2016. No ano de 2016 foram submetidos 186 artigos para avaliação, 35 foram aprovados e 25 publicados. Muitas das rejeições, de acordo com Fernandes (2016), ocorreram devido à inadequação dos artigos ao foco e escopo da Revista, bem como, em virtude das temáticas abordadas não serem pertinentes àquelas elencadas/avaliadas.

A relevância da Revista é tamanha que ao se pesquisar pelo termo de busca "Revista Brasileira de Estudos Urbanos e Regionais" no Google Scholar ${ }^{11}$, são encontrados mais de 97.000 resultados, com artigos sendo citados por mais variados trabalhos, nacionais e internacionais. Em todo o seu histórico, até o presente momento (v. 20, n. 2, maio/ago. 2018), foram publicados 322 artigos. Os seis primeiros, na edição n. 1 de 1999, foram resultados dos melhores artigos das sessões temáticas inscritos no 8 ㅇ Encontro Nacional da ANPUR, conforme apontou Gonçalves (1999, p. 3):

O conjunto dos trabalhos demonstra a diversidade de pensamento e a maturidade e rigor que a ANPUR alcançou como forum de discussão - teórica, metodológica e empírica -, base fundamental para almejar editar uma revista acadêmica. Apesar do processo de escolha aparentemente descosturado (o melhor artigo de cada sessão temática do 8 ㅇ Encontro Nacional, selecionado cada um pela respectiva comissão de seleção) o conjunto assim composto mostra-se não somente harmônico, mas articulado numa certa discussão.

\footnotetext{
${ }^{11}$ Disponível em:https://scholar.google.com.br/. Acesso em: 27 jul. 2018.
} 
Desta forma, entendendo a grandiosidade da RBEUR, o presente trabalho buscou realizar uma análise das publicações, desde sua criação até a edição corrente (v. 20, n. 2 maio/ago. 2018), focando na busca pela identificação da (s) temática(s) central(is) dos artigos.

\section{METODOLOGIA DE COLETA E ANÁLISE DOS DADOS}

Tendo em vista satisfazer o objetivo central deste trabalho, levantar o panorama acerca das temáticas abordadas nas publicações (artigos ${ }^{12}$ ) na RBEUR, inicialmente se partiu de um estudo bibliométrico ${ }^{13}$, ou seja, análise de aspectos quantitativos da produção científica a partir da organização de dados em arquivos ou planilhas (RIZZI et al., 2018), no caso deste trabalho, com uso do Pacote Office (Microsoft Excel).

Sendo assim, a pesquisa apresentada é descritiva em relação aos objetivos e quantitativa no que tange aos dados tabulados. Descritiva, pois se tem como intenção a descrição das temáticas abordadas pelos artigos publicados na RBEUR de 1999 a 2018, se pautando em análise de conteúdo para a classificação da temática. Quantitativa devido ao procedimento adotado para a busca das informações e divulgação dos resultados. A busca pelos artigos somente foi possível em virtude da disponibilidade da Revista em base de dados digital, de fácil acesso, que, por sua vez, foi muito importante para a realização desta análise ora apresentada.

Posto isto, a primeira etapa da pesquisa consistiu na classificação das temáticas a serem verificadas nos artigos. A priori, se optou em permanecer (e adaptar algumas) com aquelas vinte listadas pela própria revista em seu "foco e escopo". A seleção do período, uma tarefa pouco fácil, ocorreu em virtude da importância dos artigos publicados na RBEUR. Diante disto, mesmo com tamanha carga de trabalho, se optou em analisar todos os artigos publicados, de 1999 (n. 1, maio 1999) a 2018 (v. 20, n. 2, maio/ago. 2018), última edição publicada até a finalização do presente estudo. Desta forma, $100 \%$ dos artigos publicados foram tabulados. Cabe frisar que a análise das instituições de origem dos autores, bem como, país/região foi realizada a partir dos metadados ${ }^{14}$ disponibilizados.

Durante o processo de análise se verificou a necessidade de elencar mais quatro temáticas, tendo em vista que aquelas especificadas a priori não eram "suficientes" para enquadrar todos os textos de forma satisfatória. Assim, foram 24 (vinte e quatro) temáticas utilizadas como critérios de enquadramento dos textos: 1) planejamento e gestão urbana e/ou regional; 2) história da cidade e do urbanismo; 3) arquitetura e urbanismo; 4) produção e estruturação da cidade e/ou da metrópole e sintaxe urbana; 5) economia urbana e regional; 6) geografia regional e/ou urbana; 7) demografia; 8) política habitacional, financiamento e regulação estatal; 9) políticas públicas de desenvolvimento urbano e/ou regional; 10) formação econômico-territorial, integração e disparidades regionais; 11) desenvolvimento econômico e espaço; 12) redes, cadeias de valor, arranjos produtivos locais; 13) impactos lo-

\footnotetext{
12 Não foram analisadas "memórias da presidência", "homenagens", "conferências" e "resenhas".

${ }^{13}$ Neste trabalho não se aplicaram métodos a partir das chamadas "leis da bibliometria" descritas por Rizzi et al. (2018).

14 Os metadados foram utilizados para coleta de informações sobre a instituição de origem do autor (ou autores) das publicações, bem como, para identificar a temática abordada no texto, tendo em vista a informação da(s) área(s) do conhecimento. Nem todos os trabalhos possuíam a área informada, dificultando o processo de análise e enquadramento da temática de acordo com o "desejado" pelo(s) autor(es) do texto. Neste caso, os textos foram analisados, mediante leitura, para posterior classificação nas temáticas. Salienta-se que em muitos dos textos mais de uma temática foram identificadas.
} 
cais/regionais de políticas públicas e estratégias nacionais e globais; 14) metrópoles e/ou cidades médias; 15) redes urbanas, sistemas e hierarquias urbano-regionais; 16) relações centro-periferia, cidade e região; 17) desenvolvimento urbano-regional, tecnologia e inovação; 18) meio ambiente e sustentabilidade de cidades e regiões; 19) dinâmica econômica, modelagem e indicadores de desenvolvimento regional; 20) cultura, identidades e apropriação do espaço; 21) participação social no processo de planejamento; 22) estudo sobre a área de Planejamento urbano e regional; ou Pós-Graduação; 23) cartografia/geoprocessamento no/para planejamento territorial; e 24) movimentos sociais.

Quanto ao número de textos analisados ${ }^{15}$, foram um total de 322 (trezentos e vinte e dois) sendo necessários mais de dois meses para completa análise e tabulação ${ }^{16}$. Por fim, visando facilitar a representatividade dos dados, os mesmos foram representados visualmente (gráficos) ${ }^{17}$, seguidos de comentários, conforme exposto na próxima seção.

\title{
5 DADOS E ANÁLISE: DE ONDE E QUAIS SÃO AS TEMÁTICAS DAS PUBLICAÇÕES DA RBEUR (1999-2018)?
}

Considerando a média de artigos por volume, se verificou oscilações ao longo do período: a) nas primeiras edições, a média de artigos publicados era 6; b) dos volumes de 2008 a 2011 a média observada foi de 7 artigos; já, c) dos volumes de 2012 a 2015 a média aumentou para 11 artigos por volume; e, por fim, d) considerando os volumes de 2015 a 2018 a média observada foi de 9 artigos por volume, caracterizando aumento geral do número de artigos publicados por edição. Como já mencionado, a primeira edição, n. 1 de 1999, publicou seis artigos, sendo estes os reflexos das discussões da ANPUR naquele momento. E assim,

\begin{abstract}
As afinidades mais aparentes entre os artigos sugeririam identificar duas áreas de discussão: uma, travada no campo mais específico do Planejamento, e outra, no campo mais geral dos Estudos Urbanos. Uma outra leitura, porém, tenderia a agrupá-los não pelo campo temático comum, mas, pelo ângulo do olhar e pela intenção da procura que moveram o pesquisador. Desta perspectiva, podem ser identificados três pares de diálogos, em meio a uma postura comum de reflexão rigorosa e crítica com relação ao saber existente. (GONÇALVES, 1999, p. 3).
\end{abstract}

Em quatro deles a temática central foi o "planejamento e gestão urbana" e destes, dois ainda abordaram a questão do "urbanismo". Enquanto que os outros dois artigos tiveram como temática a "segregação social urbana". Para Gonçalves (1999), tais artigos foram construções criativas e rigorosas, propondo algo novo a pensar. Desta forma,

\begin{abstract}
A revista cria outros momentos de encontro, além daquele que se realiza pessoal e nacionalmente a cada dois anos (o encontro da ANPUR); são encontros silenciosos porém vivos, densos, plenos de troca: primeiro, entre todos os que participam do processo da sua preparação; depois, entre autores e leitor, que é o objetivo dessa realização. (GONÇALVES, 1999, p. 4).
\end{abstract}

Assim sendo, iniciando de fato as análises a partir da metodologia proposta, quanto à origem dos trabalhos, se pode verificar que foram publicados artigos oriundos de 16 países, além do Brasil, sendo que em alguns casos ocorreram publicações com parceria entre países

\footnotetext{
${ }^{15}$ Artigos.

${ }^{16}$ Início dos trabalhos na primeira quinzena de março de 2018.

${ }^{17}$ Com uso do Microsoft Excel.
} 
(pesquisadores do Brasil e Canadá, por exemplo). Estas publicações oriundas de demais países representaram aproximadamente $13 \%$ do total publicado. 0 montante publicado é assim distribuído geograficamente (Gráfico 3):

Gráfico 3 - Países de origem das publicações na RBEUR (1999-2018)

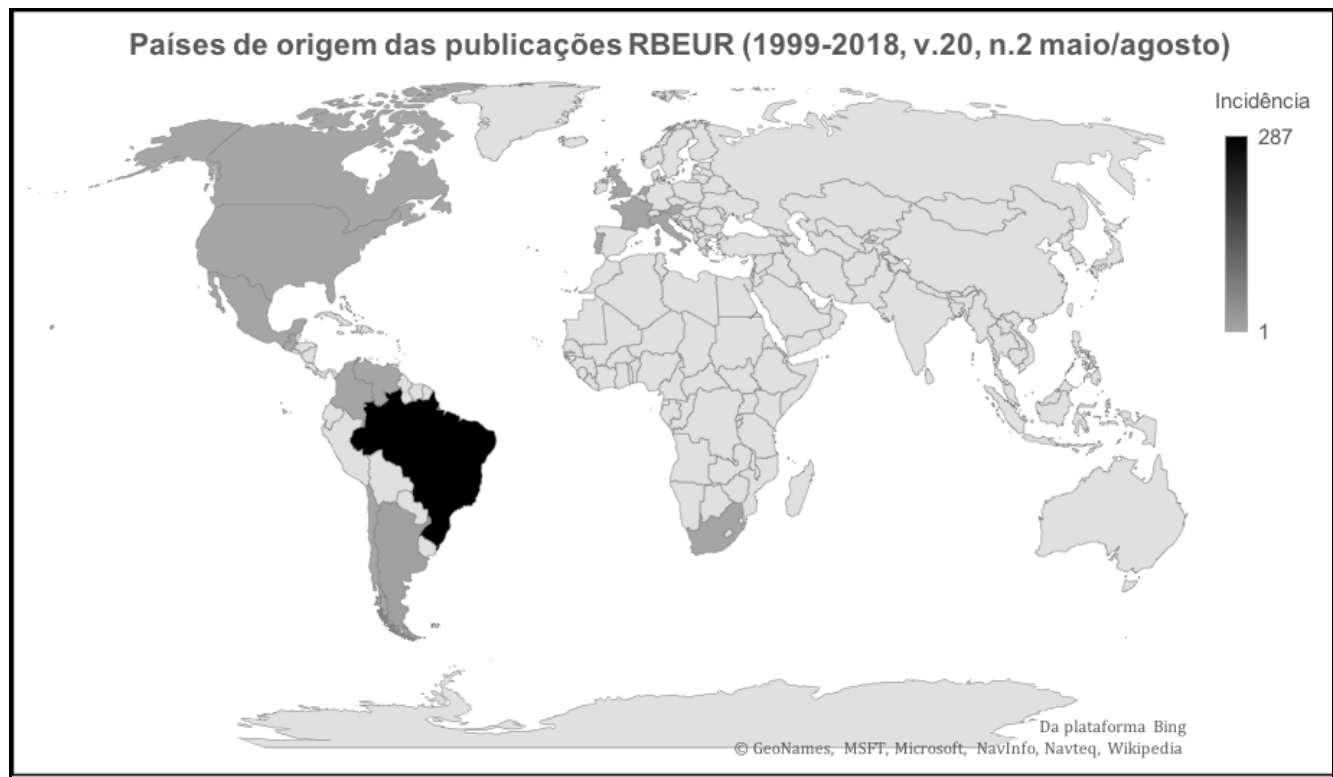

Fonte: elaborado com base nos dados da pesquisa e auxílio do Software Microsoft Excel (2018).

Como era de se esperar, o Brasil é o país de origem predominante dos artigos publicados na revista no período. Ainda, se destacam alguns países da América Latina: Argentina, México e Colômbia. Ademais, analisando somente produções oriundas de instituições brasileiras, são muito significativas aquelas das instituições da região Sudeste, representando $65 \%$ do total. As regiões Sul e Nordeste vêm em seguida com $14 \%$ e 13\%, respectivamente, e as regiões Norte e Centro-Oeste com 4\% e 3\%, nesta ordem. (Gráfico 4).

Gráfico 4 - Quantidade de publicações por período e região brasileira (1999-2018)

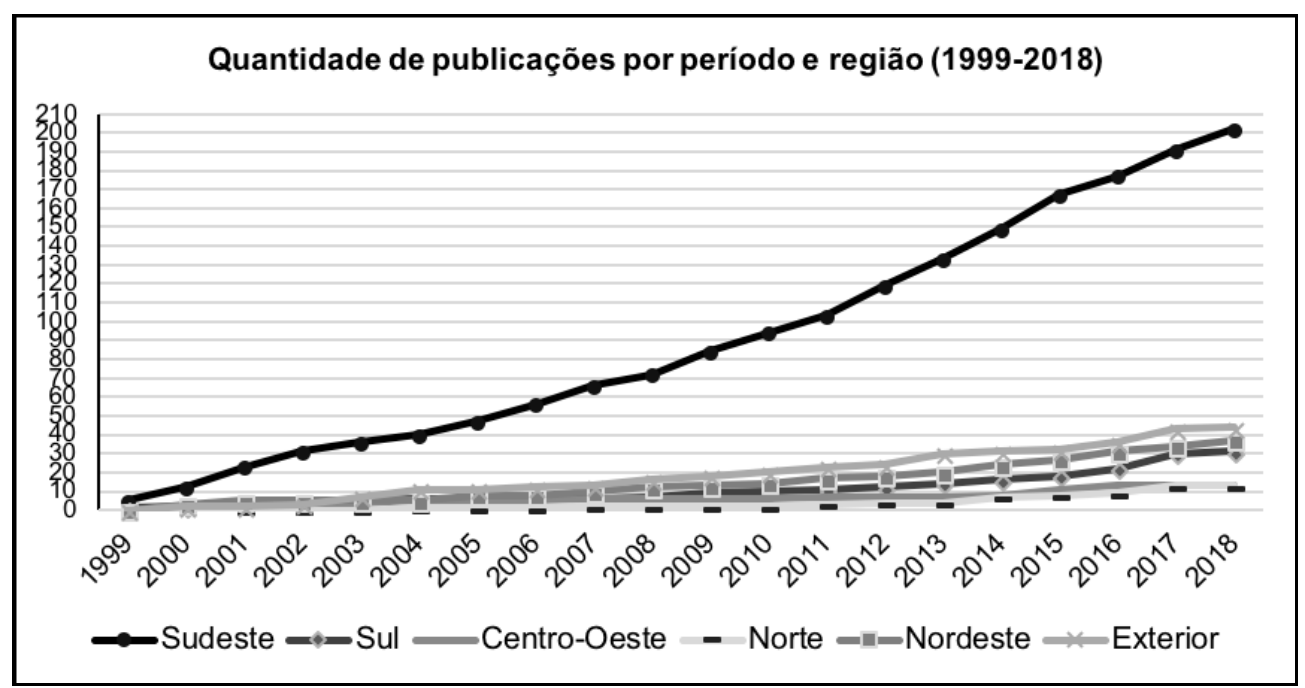

Fonte: elaborado com base nos dados da pesquisa (2018). 
Como observado, há uma discrepância da região Sudeste em relação às demais. Ainda, se pode destacar que as instituições de destaque nas publicações são assim apresentadas: a) da região Sul - publicações da UFSC (Santa Catarina) e UFRGS (Rio Grande do Sul) representam maior parte; b) da região Nordeste, embora seja a terceira região que mais publicou, não há uma "centralidade" institucional, ou seja, as publicações são oriundas de diferentes instituições da região, com certo destaque para UFPE (Pernambuco); diferente da c) região Sudeste - em que há "centralidade" de publicações originárias da USP (São Paulo), UFMG (Minas Gerais) e UFRJ (Rio de Janeiro).

Nas primeiras edições da Revista, até a primeira metade do ano de 2007, a concentração das instituições de origem das publicações era $70 \%$ da região Sudeste. Atualmente, a concentração é de 65\%, ainda alta, porém, em diminuição. Considerando as Unidades Federativas, assim estão distribuídas as publicações (Gráfico 5):

Gráfico 5 - Unidades Federativas de origem dos artigos publicados na RBEUR (1999-2018)

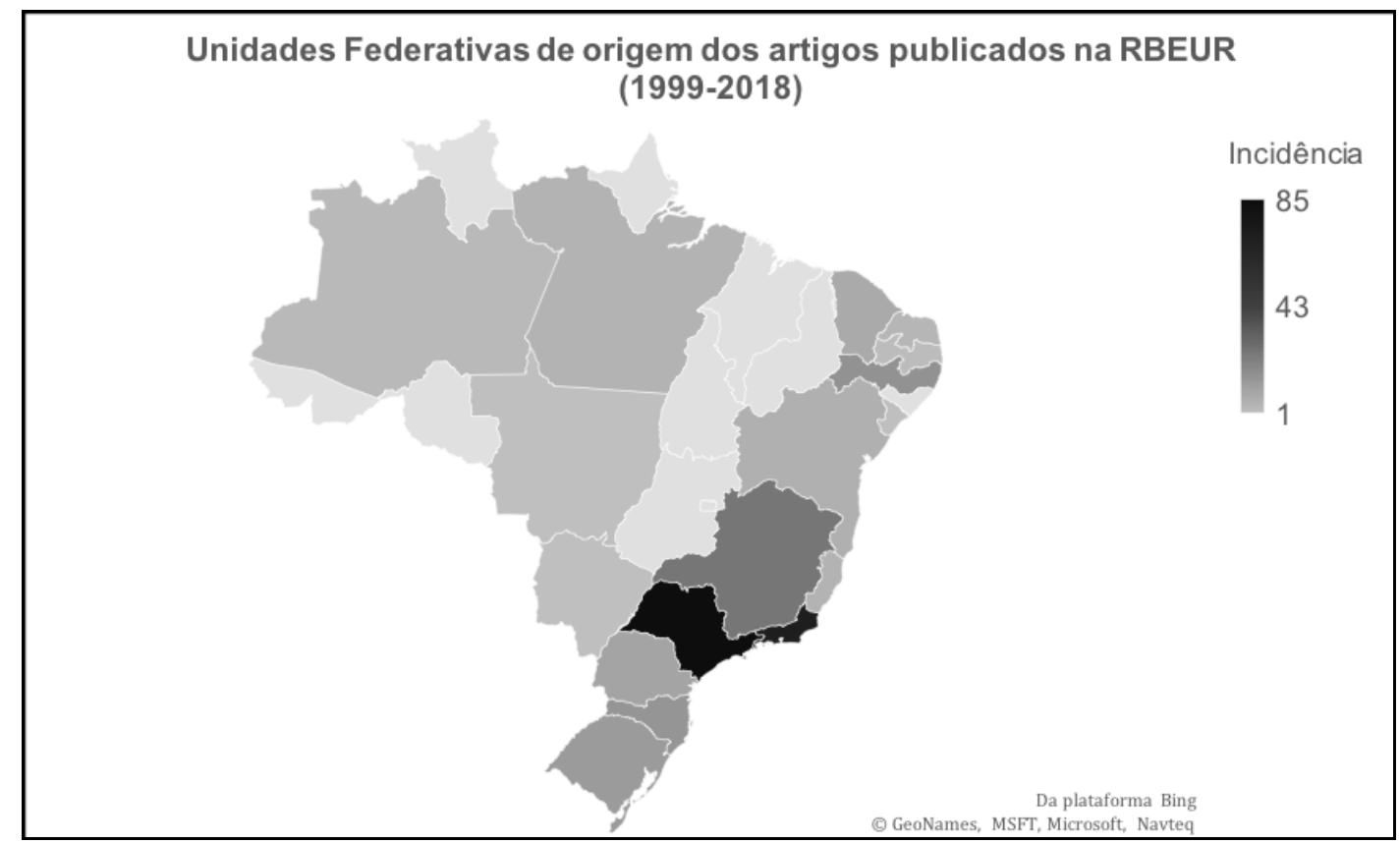

Fonte: elaborado com base nos dados da pesquisa e auxílio do Software Microsoft Excel (2018).

Seria uma coincidência as maiores quantidades de publicações advirem das regiões Sudeste, Sul e Nordeste? Talvez não, tendo em vista que é justamente nestas regiões em que estão concentradas as instituições com Programas de Pós-Graduação na área PLURD da CAPES. Ainda, todas as instituições que apresentam maior significância na quantidade de publicações (do total) são de status jurídico federal. Sobre as temáticas abordadas pelos pesquisadores da área, Piquet e Ribeiro (2008) destacaram que na década de 1950 e início de 1960 os temas eram voltados ao planejamento para a mudança e relevância da questão do desenvolvimento; na década de 1970 e início de 1980, voltados para a discussão do planejamento tecnocrático (tema que atualmente é utilizado como contraponto de críticas, como por exemplo, faz Pereira $(2015,2017)$ ) e controle da escala nacional; nas décadas de 1980 e 1990, predominavam os temas de gestão e centralidade atribuídas às forças de mercado; nos anos 2000, se retomaram as discussões sobre a questão do desenvolvimento e crescente preocupação com o planejamento - urbano e/ou regional - de longo prazo, este último, muito presente ainda nos anos pós 2010. 
Assim, considerando as temáticas abordadas, conforme já apresentada a metodologia, se infere que "planejamento e gestão urbana e/ou regional" é a temática mais recorrente (Gráfico 6).

Gráfico 6 - distribuição das temáticas (por incidência) das publicações na RBEUR (1999-2018)

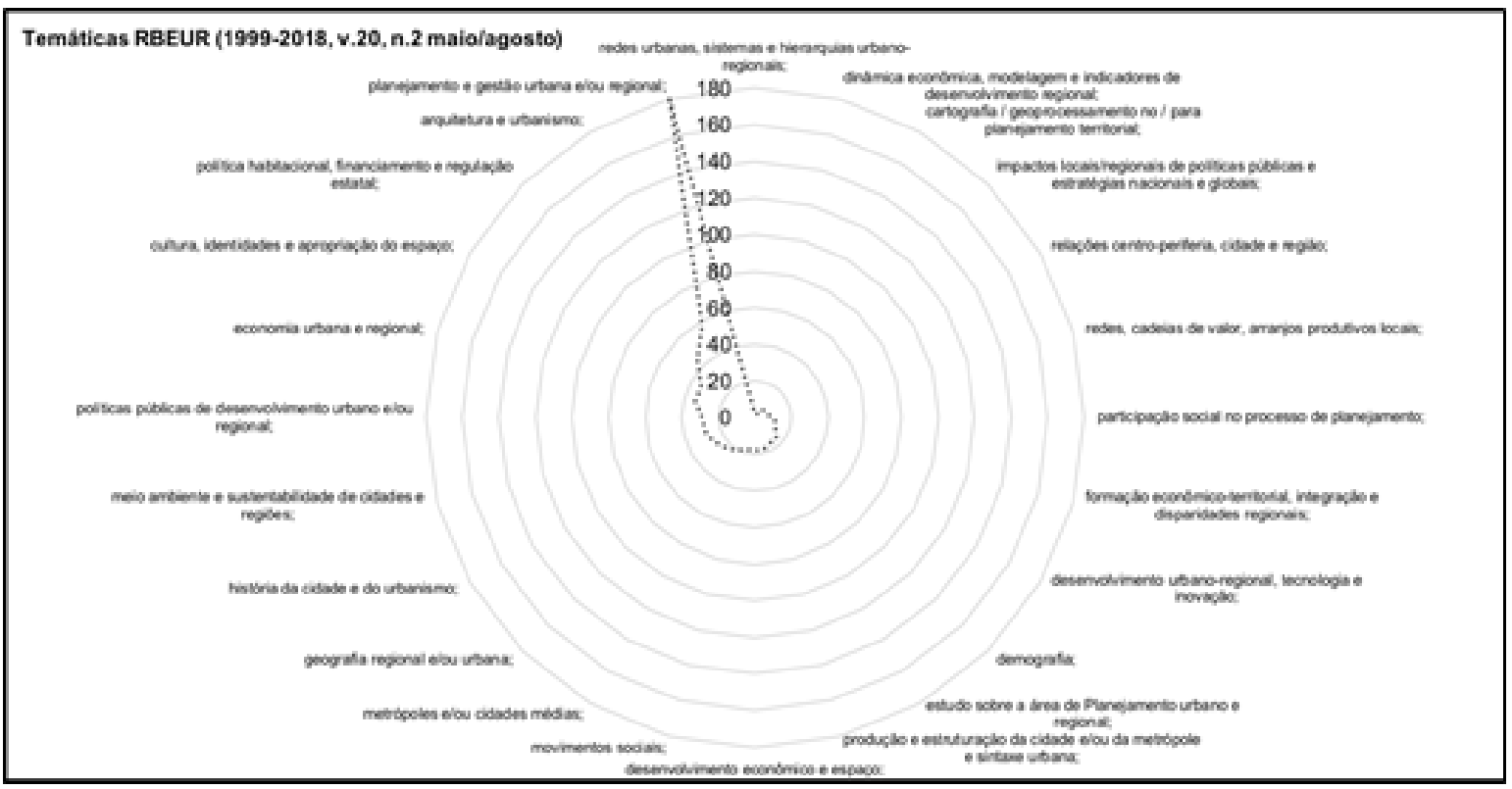

Fonte: elaborado com base nos dados da pesquisa e auxílio do Software Microsoft Excel (2018).

Excluindo da análise a temática mais recorrente, para facilitar a visualização das demais, se tem que "arquitetura e urbanismo", "política habitacional, financiamento e regulação estatal", "cultura, identidades e apropriação do espaço", "políticas públicas de desenvolvimento urbano e/ou regional", "sustentabilidade e meio ambiente" e "economia urbana e regional" foram os temas mais abordados nas publicações (Gráfico 7).

Gráfico 7 - temáticas das publicações na RBEUR (1999-2018) - excluindo a temática mais recorrente (percebida no gráfico 6)

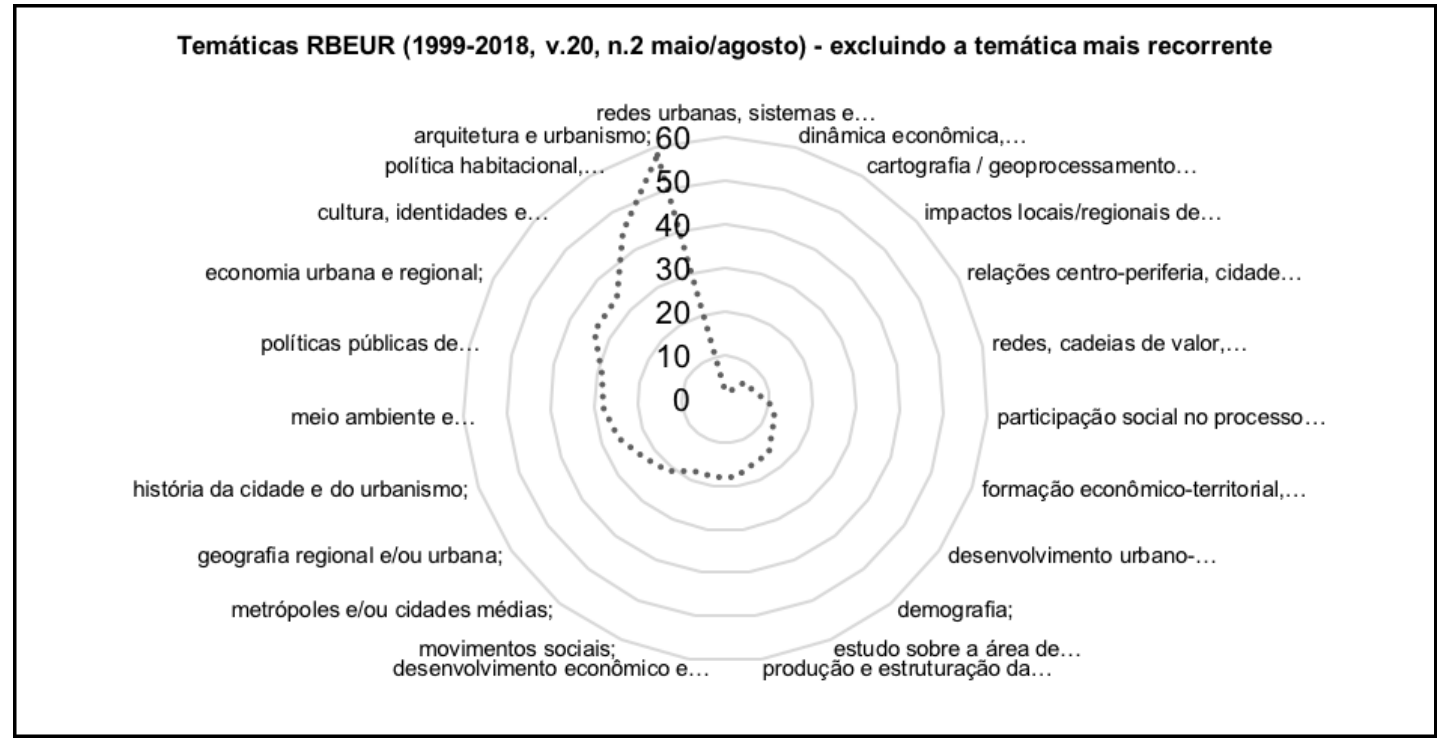

Fonte: elaborado com base nos dados da pesquisa e auxílio do Software Microsoft Excel (2018). 
Ressalta-se que em grande parte das publicações classificadas na temática mais recorrente, estão conjuntamente com outra(s) temática(s) como, por exemplo, a correlação entre "planejamento e gestão urbana e / ou regional" e "arquitetura e urbanismo". Por sinal, as primeiras edições da Revista, até a primeira metade do decênio dos anos 2000, tinham como destaque as temáticas de "história do urbanismo", "arquitetura e urbanismo" e discussões sobre metrópoles / metropolização.

Ainda, cabe destaque para as aberturas da Revista para publicações acerca da temática e de análises sobre a área de Planejamento Urbano e Regional; ou Pós-Graduação, inclusive, na edição de 2002, que em uma única publicação reuniu dois números (1/2) e abordou como foco de análise a Pós-Graduação no Brasil, bem como, discussões sobre a ANPUR. Após o ano de 2001, quando da instituição da Lei 10.257/2001 (Estatuto da Cidade) foram mais recorrentes as discussões sobre o referido Estatuto, sobretudo, demonstrando suas "limitações", assim como fizeram Galvão (2005), Gondim (2008) e Rezende et al. (2009). Ainda, temáticas como "participação nos processos de planejamento" e "movimentos sociais" também foram percebidas, especialmente, no período pós 2010, como pode ser visto em Pereira (2017) e Giaretti (2017). Porém, estas temáticas figuram ainda com menor incidência. Considerando os 19 anos de publicações, muitas foram as temáticas abordadas. Tamanha quantidade é dada pelo fato, conforme apontado pelo relatório da CAPES de avaliação quadrienal 2017 (2013-2016), por ser uma característica dos Programas da Área PLURD: a sua interdisciplinaridade ${ }^{18}$. Desta forma, o periódico permite que diversas sejam as temáticas de pesquisa e discussões abordadas, contribuindo com o processo de planejamento territorial (urbano e/ou regional).

\begin{abstract}
A interdisciplinaridade ou a realização de uma investigação interdisciplinar precisa levar em consideração muito mais do que um conjunto de disciplinas que será apropriado para dar conta da complexidade - cada vez maior - dos objetos de suas atividades. A interdisciplinaridade exige uma reflexão inicial sobre a relação entre a prática da investigação e a práxis da atuação do investigador, a necessidade de identificar as potencialidades e limitações que derivam da relação entre sujeito e objeto de investigação e das suas possíveis consequências que os resultados podem trazer para essa relação. (RANDOLPH, 2013, p. 27).
\end{abstract}

De acordo com o Relatório de Avaliação 2017 da CAPES, a interdisciplinaridade e os diálogos variaram de intensidade de acordo com a instituição em que os Programas estão sediados. Em processo análogo, é possível se pensar que a produção intelectual, sobretudo de artigos científicos para publicação em periódicos (qualificados), é o resultado de sujeitos atuando em conjunto visando atender a certas expectativas, no caso, ao planejamento territorial (urbano e/ou regional).

Ribeiro $(2002$, p. 66) destacou que na história acadêmica da área PLUR, há “[...] acúmulos reflexivos decorrentes da efetiva vivência do diálogo entre disciplinas [...]", resultado da falta de diálogos e reflexões coletivas, podendo resultar em "[...] obstáculos à compreensão das expectativas daqueles que procuram a pós-graduação na área, retendo a transmissão intergeracional do conhecimento." (RIBEIRO, 2002, p. 67). Compreende-se que a produção intelectual é o resultado destes diálogos e reflexões coletivas. E nos parece que tais reflexões estão polarizadas nas regiões Sudeste, Sul e Nordeste, estas duas últimas, em menor intensidade. Assim como é preciso descentralizar os Programas na área PLURD, é igualmente

\footnotetext{
${ }^{18}$ Porém, para Randolph (2013) falta uma consolidação de "perspectivas interdisciplinares" que surgem das práticas.
} 
necessária a pulverização das instituições de origem das publicações na RBEUR (?), a partir do estímulo de novos Programas na área (descentralizando-os), bem como, da produção (intelectual) de Programas já instalados (?).

\section{NOTAS FINAIS: PARA ONDE SE CAMINHA?}

Diante do exposto no texto apresentado, se constata o aumento do número de Programas de Pós-Graduação na área de PLURD da CAPES nas últimas duas décadas. Porém, ainda há uma lacuna nas regiões Norte, Nordeste e Centro-Oeste. Além do mais, são poucos os Programas Profissionais, oito no total. No que diz respeito aos Doutorados, se expõe a ausência de Programas na área PLURD na região Centro-Oeste. Já, na região Norte, há um Programa de Doutorado no estado do Tocantins, o que, por sua vez, está distante, geograficamente, das demais Unidades Federativas da região.

A RBEUR, como importante braço da ANPUR, iniciou suas publicações (1999) pouco tempo antes do processo de expansão mais "acentuado" dos Programas de Pós-Graduação na área PLURD, a partir dos anos 2000. Diante dos resultados da análise de conteúdo em 19 anos de publicações da RBEUR, se constatou que a temática "planejamento e gestão urbana e/ou regional" foi predominante nos textos (artigos). Embora se tenha percebido publicações originárias de todas as regiões do país, bem como de alguns países do exterior (sobretudo da América Latina, conforme Gráfico 3), estas publicações, por sua vez, são concentradas por instituições da região Sudeste do Brasil de status jurídico federal.

Por ser uma Revista que tem como foco à área de PLURD da CAPES, é em sua essência, interdisciplinar. Esta interdisciplinaridade, ao analisar as temáticas apresentadas no "foco e escopo", é percebida, por exemplo, em:

- arquitetura e urbanismo - relacionada a área de arquitetura e urbanismo, engenharias;

- economia urbana e regional; redes, cadeias de valor, arranjos produtivos locais; formação econômico-territorial, integração e disparidades regionais - relacionadas à área de economia;

- política habitacional, financiamento e regulação estatal; políticas públicas de desenvolvimento urbano e regional - relacionada a área de administração;

- desenvolvimento urbano-regional, tecnologia e inovação - relacionada à área de tecnologia; meio ambiente e sustentabilidade de cidades e regiões - relacionada à área das ciências ambientais, biológicas etc.;

- cultura, identidades e apropriação do espaço - relacionada à área de antropologia, sociologia;

Porém, frisa-se que a verdadeira interdisciplinaridade é aquela, não obstante às discussões teóricas, que resulta da relação reflexiva e responsiva da junção de diversas áreas (na prática), frutificando assim num processo de planejamento positivo, menos tecnocrático, como devem ser o planejamento e a gestão urbana e regional, conforme enfatizam diversos artigos na própria Revista e que os autores deste texto pactuam.

A diversidade de temáticas da Revista reforça a interdisciplinaridade da área PLURD e se espera que estas possam contribuir para discussões ou para as aplicabilidades práticas, no caso de Mestrados Profissionais. Espera-se, ainda, sempre contribuir com o progresso (de longo prazo), seja em nível urbano, regional ou mesmo global, e esta é a essência da Revista, conforme visto pelo relato de Gonçalves (1999). Talvez, a temática "planejamento e gestão 
urbana e/ou regional" foi destaque durante todo o período analisado, pois, é aquela em que mais se pode interdisciplinarizar, sendo mais "aberta" e/ou "abrangente".

Cada vez mais se caminha para a interdisciplinaridade, buscando contribuições e elementos de diferentes áreas a fim de promover positivo desenvolvimento, estudando diferentes abordagens, pois a RBEUR está, desde sua primeira edição, propondo algo novo a pensar e discutindo aquilo que é destaque em diferentes períodos. Atualmente, se percebe no caso de debates sobre mobilizações sociais no processo de planejamento, ou mesmo participação social, como, por exemplo, abordado por Giaretti e Di Giulio (2017), quando discutem o papel das tecnologias de comunicação e informação (TIC) ${ }^{19}$ no contexto urbano do século XXI e na emergência dos novos movimentos sociais, realizando reflexões a partir de experiências na Megacidade de São Paulo.

Posto isto, finaliza-se destacando que a RBEUR, no âmbito da disseminação da informação e do conhecimento, tem se mostrado propositiva a discussões sobre temáticas interdisciplinares, que certamente contribuem com o processo de desenvolvimento em todas as escalas, inclusive, e, sobretudo, no âmbito crítico-reflexivo, teórico e prático.

\section{REFERÊNCIAS}

ANPUR. Associação Nacional de Pós-graduação e Pesquisa em Planejamento Urbano e Regional (ANPUR). Disponível em: http://anpur.org.br/sobre-a-anpur/. Acesso em: 29 jul. 2019.

CENTRO DE GESTÃO E ESTUDOS ESTRATÉGICOS (CGEE). Doutores 2010: estudos da demografia da base técnico-científica brasileira. Brasília, DF: CGEE, 2010. Disponível em: https://www.cgee.org.br/documents/10195/734063/Doutores2010 demografiall 02052012 7842.p df. Acesso em: 29 jul. 2019.

COORDENÇÃO DE APERFEIÇOAMENTO DE PESSOAL DE NÍVEL SUPERIOR (CAPES). Relatório de Avaliação do Quadriênio 2017 (2013-2016). Disponível em:

http://capes.gov.br/images/documentos/Relatorios quadrienal 2017/RELATORIO AVALIACAO QUA DRIENAL 2017 FINAL reunido.pdf. Acesso em: 29 jul. 2019.

FERNANDES, A. C. Revista Brasileira de Estudos Urbanos e Regionais (RBEUR): relatório. [S. I.], 2016. Disponível em: http://www.anpur.org.br/Relatorio RBEUR 2016.pdf. Acesso em: 29 jul. 2019.

FISCHER, L. R. C.; SIQUEIRA, L. A. A política de regularização fundiária urbana de interesse social: algumas conclusões a partir da pesquisa nas regiões Norte e Nordeste. In: NOBRE; E.; D’OTTAVIANO, C. Caderno de Resumos - XVII Encontro Nacional da Associação Nacional de Pós-Graduação e Pesquisa em Planejamento Urbano e Regional. São Paulo: Faculdade de Arquitetura e Urbanismo da Universidade de São Paulo, 2017.

\footnotetext{
${ }^{19}$ Há uma tese de doutoramento em andamento no Programa de Pós-Graduação em Planejamento Territorial e Desenvolvimento Socioambiental da Universidade do Estado de Santa Catarina (UDESC) que está abordando a relação entre ciberespaço, TICs (fenômeno mais recente) e planejamento territorial participativo, ficando evidente que estas novas temáticas estão sendo exploradas pela área. Como a área PLURD "absorve", por ser interdisciplinar, os resultados tendem a ser muito positivos.
} 
GALVÃO, O. Externalidades e desenvolvimento urbano: reflexões a partir do Estatuto da Cidade. Revista Brasileira de Estudos Urbanos e Regionais, [S. I.], v. 7, n. 2, p. 27-45, nov. 2005. Disponível em: https://rbeur.anpur.org.br/rbeur/article/view/143/127. Acesso em: 29 jul. 2019.

GIARETTI, J. B. Z.; DI GIULIO, G. M. O papel das tecnologias de comunicação e informação (TIC) no urbano do século XXI e na emergência dos novos movimentos sociais: reflexões a partir de experiências na Megacidade de São Paulo. Revista Brasileira de Estudos Urbanos e Regionais, [S.I.], v. 20, n. 1, p. 161, nov. 2017.

GONÇALVES, M. F. Editorial: Aleluia!. Revista Brasileira de Estudos Urbanos e Regionais, [S. I.], n. 1, p. 3-4, maio 1999. Disponível em:

https://rbeur.anpur.org.br/rbeur/article/view/18/6. Acesso em: 29 jul. 2019.

GONDIM, Linda M. P. A favela depois do Estatuto da Cidade: novos e velhos dilemas à luz do caso do Poço da Draga (Fortaleza-CE). Revista Brasileira de Estudos Urbanos e Regionais, [S. I.], v. 10, n. 2, p. 97-114, nov. 2008. Disponível em:

https://rbeur.anpur.org.br/rbeur/article/view/202/186. Acesso em: 29 jul. 2019.

LIMONAD, E. Lá se vão trinta anos de ANPUR.... Revista Brasileira de Estudos Urbanos e Regionais, [S. I.], v. 19, n. 2, p. 219-232, abr. 2017. Disponível em:

https://rbeur.anpur.org.br/rbeur/article/view/5567/4783. Acessado em: 29 jul. de 2019.

MARICATO, E. O lugar fora das ideias e as ideias fora do lugar. In: ARANTES, O.; VAINAR, C.; MARICATO, E. A cidade do pensamento único. Desmanchando consensos. Petrópolis, RJ: Vozes, 2009.

NOBRE; E.; D'OTTAVIANO, C. Caderno de Resumos - XVII Encontro Nacional da Associação Nacional de Pós-Graduação e Pesquisa em Planejamento Urbano e Regional. São Paulo: Faculdade de Arquitetura e Urbanismo da Universidade de São Paulo, 2017.

PEREIRA, E. M. Alegoria da participação: planos diretores participativos pós-estatuto da cidade. Florianópolis: Insular, 2015.

PEREIRA, E. M. Como anda a participação? As condições para a elaboração de Planos Diretores Participativos. Revista Brasileira de Estudos Urbanos Regionais, [S. I.], v. 19, n. 2, p. 235250, maio/ago. 2017. Disponível em:

https://rbeur.anpur.org.br/rbeur/article/view/5380/pdf. Acesso em: 29 jul. 2019.

PIQUET, R. P. S.; RIBEIRO, A. C. T. Tempos, idéias e lugares: o ensino do Planejamento Urbano e Regional no Brasil. Revista Brasileira de Estudos Urbanos e Regionais, [S. I.], v. 10, n. 1, p. 49-59, maio 2008. Disponível em: https://rbeur.anpur.org.br/rbeur/article/view/191/175. Acesso em: 29 jul. 2019.

PIQUET, R.; VILANI, R. M. O papel dos mestrados profissionais na área de Planejamento Urbano e Regional. Revista Brasileira de Estudos Urbanos e Regionais, [S. I.], v. 15, n. 1, p. 95- 
106, maio 2013. Disponível em: https://rbeur.anpur.org.br/rbeur/article/view/4172/4056. Acesso em: 29 jul. 2019.

PORTO, J. L. R.; THEIS, I. M. A Pós-Graduação em Planejamento Urbano e Regional no Brasil: quatro décadas de reflexões territoriais. PRACS: Revista Eletrônica de Humanidades do Curso de Ciências Sociais da UNIFAP, v. 9, p. 33-46, 2016.

RANDOLPH, R. Em busca de uma agenda para o Planejamento Urbano e Regional: uma homenagem a Ana Clara Torres Ribeiro. Revista Brasileira de Estudos Urbanos e Regionais, [S. I.], v. 15, n. 1, maio 2013. Disponível em:

https://rbeur.anpur.org.br/rbeur/article/view/4168/4052. Acesso em: 29 jul. 2019.

REZENDE, V. F. et al. A Outorga Onerosa do Direito de Construir e o Solo Criado: uma necessária avaliação das matrizes conceituais. Revista Brasileira de Estudos Urbanos e Regionais, [S. I.], v. 11, n. 2, p. 51-71, nov. 2009. Disponível em:

https://rbeur.anpur.org.br/rbeur/article/view/220/204. Acesso em: 29 jul. de 2019.

RIBEIRO, A. C. T. O ensino do Planejamento Urbano e Regional: propostas à ANPUR. Revista Brasileira de Estudos Urbanos e Regionais, [S .I.], v. 4, n. 1/2, p. 63-72, maio 2002. Disponível em: https://rbeur.anpur.org.br/rbeur/article/view/75/59. Acesso em: 29 jul. 2018.

RIZZI, D. I. et al. O modelo da hélice tríplice: produção intelectual em periódicos nacionais e internacionais. Revista Gestão Universitária na América Latina - GUAL, Florianópolis, v. 11, n. 12, p. 110-132, jun. 2018.. Disponível em:

https://periodicos.ufsc.br/index.php/gual/article/view/1983-4535.2018v11n2p110/36889. Acesso em: jul. de 2018. 